\section{Questión}

Periodismo / Comunicación ISSN 1669-6581

Historia y evolución de la Producción Radiofónica

Julieta Dussel

Question/Cuestión, Vol. 2, № 66, Agosto 2020

ISSNe 1669-6581

https://perio.unlp.edu.ar/ojs/index.php/question/index

IICom-FPyCS-UNLP

\title{
HISTORIA Y EVOLUCIÓN DE LA PRODUCCIÓN RADIOFÓNICA
}

\section{HISTORY AND EVOLUTION OF RADIO PRODUCTION}

\section{Julieta Dussel}

Periodista. Productora de Radio y Televisión Licenciada en Ciencias de la Comunicaión - UBA

@JuliDus

\section{Resumen}

Julieta Dussel a partir de su compromiso e historia profesional, reflexiona sobre las transiciones en los modos de producir, ordenar, tomar decisiones y ejecutar los proyectos radiales. Desde el caso, nos pasea por momentos clave de la radio y arriesga ideas que invitan a pensar e oficio.

\section{Palabras clave}

Radio, Producción, Tecnología 


\begin{abstract}
Julieta Dussel, based on her commitment and professional history, reflects on transitions in the ways of producing, ordering, making decisions and executing radio projects. From the case, he walks us through key moments on the radio and risks ideas that invite us to think and trade.
\end{abstract}

\title{
Keywords
}

Radio, Conducting, Announcer, Culture

\section{Introducción}

Empecé a trabajar en producción en radio a comienzo de la década del 90. A partir de entonces pasé por distintas radios y produje programas en diferentes horarios (menos la trasnoche, todos).

Desde ese entonces cambió mucho la manera de producir, en parte por los cambios en las tecnologías y por cómo eso fue impactando en las tareas de la producción radial. Además, en este tiempo el trabajo de producción se fue profesionalizando y cada vez fueron más los estudiantes o graduados de periodismo, comunicación social e incluso escuelas de radio quienes pasaron a formar parte de los planteles de las radios como productores, movileros, columnistas y conductores.

A comienzo de los '90 había muchas más limitaciones técnicas que en la actualidad. Los móviles de las radios se llamaban así porque salían a la calle con una camioneta, que era el soporte técnico para realizar la conexión. Fue recién en esos años que se comenzaron a utilizar los celulares, que por ese entonces eran una valija pequeña y pesada. Esos periodistas "móviles" o corresponsales grababan las entrevistas o testimonios en cassettes con sus 
"walkman", que después debían poner "en punta" (es decir en el lugar exacto desde donde debía comenzar la grabación) cuando salían al aire desde un teléfono fijo.

En general las radios AM solían tener una mayor estructura informativa con un jefe del informativo, varios redactores/locutores, móviles y acreditados en distintos lugares de interés: el Ministerio de Economía, la Casa Rosada, el Congreso, Tribunales, que se ocupaban de producir su propia información y facilitaban el trabajo de los productores (consiguiendo información o entrevistas).

Como no había internet ni portales de noticias, las radios estaban suscriptas a distintas agencias de noticias (nacionales e internacionales) que enviaban la información a través de cables de noticias, que iban quedando guardados en una computadora que uno podía consultar e imprimir (jen una impresora de papel continuo!).

Los oyentes se comunicaban telefónicamente con la radio y sus mensajes se grababan en contestadores telefónicos físicos (un aparato con un cassette) que después había que llevar al estudio auxiliar donde con un operador se seleccionaban los mensajes que se pasarían al aire, que a su vez eran copiados a una cinta abierta (no se cuanta gente sabe qué es eso hoy en día) y así se pasaban al aire.

Como una novedad en los 90 se comenzó a usar el fax, para que los oyentes pudieran comunicarse con la radio, y también lo usábamos los productores para recibir información.

Una o dos veces por día las radios solían tener panoramas de noticias. Allí los testimonios que se intercalaban eran recortados en cassettes especiales que se denominaban "en punta", porque a diferencia de los comunes no tenían 
tiempo muerto y comenzaban a grabar desde el segundo 0 , así no quedaba bache. Normalmente un panorama de noticias podía llevar 30 testimonios, que un productor llevaba organizados y numerados para que el operador pudiera seguir el orden.

Como en los '90 no existía Google, para buscar un teléfono había que recurrir a la guía telefónica, es por eso que en la mayoría de las radios había una biblioteca especialmente destinada a los tomos de las guías telefónicas de todo el país (también se podía llamar a la operadora, pero nunca contestaban).

Me acuerdo que cuando la explosión de la fábrica militar de Río Tercero fue una batalla campal de productores por ese tomo de la guía, hasta que alguien se le ocurrió fotocopiar algunas páginas.

Es por eso que en esa época el tesoro más preciado de un productor radial era su agenda. De papel, obvio. Tomos anillados de 200 páginas ordenados alfabéticamente. $Y$ había que ser organizado con esa agenda, porque no era electrónica. Uno tenía que saber dónde había agendado a cada persona, si por el nombre, el caso o su especialidad. Así que un productor debía tener una buena agenda, con miles de contactos y la mayor parte de su trabajo consistía en "producir notas", es decir concertar entrevistas que se harían durante el programa.

En los '90 eran pocas las personas que tenían un "prensa", alguien que se ocupara de la comunicación. Los Presidentes y Ministros tenían algún vocero, y algunos políticos también, pero eran pocos. Así que para concertar una entrevista con un Diputado había que llamar al conmutador de la Cámara, si uno no conocía el interno con el que quería hablar, había que esperar con mucha suerte que alguien atendiera y lo comunicaran con el despacho que necesitaba. 
La competencia entre las radios para ver quien conseguía primero "la nota" con el protagonista del día era feroz. Los programas de la mañana "abrían" con una nota, a las 9:01 de la mañana, sin casi decir ni hola. Y los productores de la mañana se mataban por conseguir "la entrevista" del día.

\section{"El Ventilador"}

En el año 1997 tuve la suerte de trabajar en "El Ventilador", el programa conducido por Jorge Guinzburg, con Adolfo Castelo y Carlos Ulanovsky. En mi caso esa experiencia implicó un aprendizaje enorme e hizo que cambiara totalmente la manera en que venía trabajando. Era un programa de la mañana que iba de 9 a 13 por Radio América, a continuación del programa de Bernardo Neustandt. En esa época había mucha competencia entre las radios y todos los programas de las 9 empezaban con una entrevista fuerte. Para mi sorpresa una de las primeras cosas que dijo Guinzburg fue: "de 9 a 10 no quiero notas". Nadie podía creer lo que estábamos escuchando, ¿cómo que no íbamos a competir con otras radios? ¿íbamos a dejar que otros programas nos sacaran las notas? ¿íbamos a llegar tarde a todo? Pero Jorge siguió, "la gente no va a escuchar nuestro programa para oír las mismas notas que en todos lados. Nos escuchan por nosotros, quieren saber lo que digo yo, lo que dice Adolfo y Carlos. Eso es lo que nos hace distintos. Nuestra mirada". Y tenía toda la razón del mundo, el Ventilador fue un éxito, es el día de hoy que hay gente que todavía recuerda el programa (y no es por los entrevistados de las 9).

En esa época en las radios estaba "prohibido" sacar a un entrevistado que ya hubiera salido el mismo día en otro programa de la emisora. Para eso había un cuaderno de producción en el que se iban registrando cada una de las notas que se hacían en los programas, así los productores podían chequear a 
quienes habían salido al aire antes y no repetir notas. Esa era una de las máximas de la producción radial "no repetir notas". Y eso respetábamos todos hasta que el rebelde de Jorge Guinzburg quiso hacer una nota con un entrevistado que había salido hacía apenas unas horas en el programa anterior. Los productores del programa tratamos de explicarle que no podíamos llamar a esa persona porque "ya había salido en el programa de Neustadt", y Jorge (con toda la razón del mundo) nos miró risueño y dijo "¿Ustedes creen que la nota que le hizo Neustadt y la que le voy a hacer yo se parecen en algo?". La entrevista se hizo, y no tuvo nada que ver. $Y$ esa regla quedó en desuso, al menos para nosotros.

El Ventilador fue un programa innovador para la $A M$ en muchos sentidos, y desde afuera podía parecer que era un programa fácil de producir: en la primera hora no se hacían notas, tampoco hacíamos tantas notas por programa (tres como mucho), sobraban talento al aire (Guinzurg, Castelo, Ulanovsky, más Gabriela Radicce y María O’Donnell), pero creo que nunca trabajé tanto en mi vida.

Todo estaba producido. El programa comenzaba con una consigna ingeniosa (teníamos una reunión semanal de producción para elegirlas) que debía ser respondida por cinco famosos (según Guinzburg un famoso era "alguien que no hace falta explicar quien es"). Eso quería decir que había que llamar a mucha gente, que no debían ser siempre los mismos, había que explicarles la consigna y conseguir que cinco aceptaran responder la consigna del día siguiente, después había que ir a un estudio auxiliar (negociar el espacio con el informativo y otros programas de la radio que grababan/editaban notas), explicarle al entrevistado que debía comenzar auto presentándose, contestar en menos de 1 minuto y rogar que su respuesta fuera graciosa o entretenida, y 
si eso no sucedía tratar de que la regrabara mejor con alguna excusa (que se había entrecortado la llamada, que hubo un problema técnico o lo que fuera) porque Jorge era muy exigente con que tenían que ser respuestas que valieran la pena. Esa consigna que representaba 5 minutos de aire al comienzo del programa llevaba al menos dos o tres horas de producción, todos los días. Y eso era solo para comenzar.

El programa estaba lleno de pequeños momentos que estaban súper producidos. Teníamos "las noticias optimistas" del día, que había que buscar y redactar (y a fines de los 90 no había muchas noticias alentadoras). Castelo hacia una especie de "pasando revista" donde más allá del talento de Adolfo (que era muchísimo) había mucho trabajo atrás: un productor debía leer cuidadosamente las revistas (Caras, Gente, Pronto, Semanario, además de los diarios) y marcar en ellas cosas llamativas, graciosas, algo que permitiera que Castelo hiciera un chiste o un comentario, después -fuera del aire- había que ver eso con Adolfo que seleccionaba las que mejor funcionaban para él y eso era lo que salía al aire.

Trabajando en radio conocí poca gente tan profesional, meticulosa y ordenada como Carlos Ulanovsky, que tenía todo anotado en hojas y "papelitos", cada cosa que pedía "Ula" tenía "un sonidito" que necesitaba para salir al aire, si iba a hablar de una película o serie que se estrenaba quería la banda sonora, el tráiler o un fragmento de una escena. Si íbamos a hablar de un músico, uno de sus temas. Y si Carlos pedía algo nunca se olvidaba que lo había pedido. Recordemos que era una época en la que no había internet, así que no se podían "bajar" esos audios de la nube, había que tener el cd del músico, hablar con el distribuidor de la película y conseguir una copia del tráiler, que era en 
VHS y después había que convertirlo a otro formato que se pudiera pasar al aire, y así con todo.

Cada día cuando terminaba el programa hacíamos una pequeña reunión de producción y semanalmente una más larga para hablar de lo que estaba funcionando y lo que no, para definir entrevistas a largo plazo, nuevas secciones y consignas. Era un programa en el que sobraba la gente talentosa, pero también había mucho trabajo. Aunque el equipo de producción tuvo algunos cambios, siempre fuimos más de 5 productores trabajando simultáneamente en el programa, algo que hoy parece imposible.

\section{La computadora, los celulares y los operadores}

A medida que pasaron los ' 90 las radios se fueron modernizando. En los controles de las radios se comenzaron a usar computadoras para operar el aire, los cassettes y las cintas abiertas le dejaron su lugar a soportes como los CD's, los mini discs y los zips, formatos digitales que permitían trackear las pistas de sonidos y editar en su interior, para que los testimonios o audios pudieran estar "en punta". A partir de ese momento se comenzaron a incorporar muchos efectos sonoros a los programas (aunque había antes operadores que eran tan genios -como Carly Cacaviello- que eran capaces de meter efectos y audios con cassettes, pero era algo sólo para habilidosos) y la posibilidad de "vestir" las notas con audios, sonidos, música, efectos se hizo mucho más accesible, y los productores debieron no sólo empezar a pensar qué nota harían y con quién, sino también cómo sería esa entrevista, qué sonidos, músicas, audios, declaraciones se podrían incluir, cómo se podía arrancar y cerrar la nota. 
Para fines de la década del '90 ya todas las radios contaban con periodistas móviles (con celulares), así que buscarle destino a los móviles comenzó a ser otra tarea que fuimos sumando los productores de los programas, muchas veces había que acordar con el informativo sobre los destinos de los móviles y también aprender a negociar sobre la pertinencia de sus apariciones al aire, porque no siempre que alguien esté en un lugar significa que tenga algo para decir y ese solía ser un punto en el que los móviles y los productores no siempre nos poníamos de acuerdo.

Los oyentes dejaron atrás el fax y pasaron a comunicarse con la radio vía mail, toda una novedad para la época. Las notas comenzaron a grabarse directamente en computadoras, lo que facilitó el trabajo de edición. Además los audios que se "bajaban" de la televisión también se comenzaron a grabar digitalmente (antes lo hacíamos en VHS), y se los pudo recortar con más facilidad. Al comienzo el trabajo de grabación y edición de audios era algo que sólo los operadores hacían, los programas de edición eran profesionales y no cualquiera podía tenerlos, pero con el tiempo comenzaron a estar disponibles para los productores, que así fuimos sumando nuevas tareas.

Algo parecido pasó con los llamados de los oyentes, que pasaron a grabarse en un contestador digital, lo que permitió a la producción escucharlos y seleccionar los elegidos para que un operador los cortara, aunque poco tiempo después fueron los productores quienes comenzaron a cortar y editar los mensajes de los oyentes, aunque eso implicó cierta resistencia de los operadores, quienes -con razón- veían recortadas sus tareas y sus puestos de trabajo. 


\section{Otra vuelta en la producción radial}

A comienzos del 2002 el programa que hacíamos con Adolfo Castelo en Radio del Plata pasó a Radio Mitre, en pleno momento de ebullición post crisis del 2001, mientras había asambleas, recambios presidenciales y mucha incertidumbre. En la producción éramos muchos, casi todos muy jóvenes, personas de lo más talentosas que conocí en el medio (el Tano Gentilli, Gerardo Delelisi, Diego Tomasi, Laura Inchauspe, Inés Rodríguez, Rodrigo Herrero y Florencia Ballarino) y aunque no siempre estuvieron todos nunca fuimos menos de 5 personas. Aunque el programa empezaba a las 3 de la tarde todos estábamos en la radio a las 11 de la mañana como tarde y en muchos casos trabajábamos desde mucho antes. Algunos desde la noche anterior grabando y recortando audios de los programas políticos de la noche, otros desde muy temprano en la mañana seleccionando y redactando las noticias que después le pasábamos a Barragán para que redactara el guión de la apertura del programa, que consistía en un repaso de las noticias del día (al menos 20), cada una con un remate humorístico o un comentario editorial breve. Ese guion -que en un principio recibíamos de Barragán vía fax y luego por email- lo editábamos con Adolfo y el Tano y recién ahí teníamos lista la apertura del programa: información, humor y mucho trabajo.

Otra de las novedades que hicimos en el programa fue que los columnistas grababan y editaban con anterioridad las entrevistas que necesitaban para los temas que trataban. Así maximizábamos el tiempo al aire, podíamos obtener declaraciones exclusivas sin que fuera necesario que todos participaran de los reportajes, además podíamos extraer sólo lo importante y dejar al aire un testimonio de no más de 3 minutos, que sumado a la columna no llevaba más 
de 10 minutos del programa, de esa manera los columnistas podían hacer dos entradas por programa (si eran breves).

En el programa usábamos muchos audios breves, de figuras muy reconocibles por su voz. Políticos como Menem, de la Rúa, Duhalde y también famosos como Susana, Mirtha, Bilardo, Maradona, etc. A quienes recortábamos en frases muy breves, que sacábamos de contexto y los hacíamos dialogar improvisadamente con Castelo, generando situaciones de humor. Eso fue algo que recién pudimos hacer en ese momento porque técnicamente se comenzó a poder grabar, recortar y editar digitalmente esos audios para después organizarlos en carpetas en una computadora y poder "dispararlos" al aire según fuera pertinente. Esto que ahora es algo que sumamente común, no lo era en su momento. Con el tiempo conseguimos incluso que nos pusieran una segunda computadora en el control de la radio desde donde podíamos disparar esos sonidos. Esa computadora la manejábamos directamente los productores (sin necesidad de un operador), fue algo excepcional porque siempre es un operador el que maneja todo lo que sale al aire, pero por la velocidad con la que improvisaba Castelo era necesario que fuera un productor que entendiera qué contenido y qué personaje podía intercalarse en esos diálogos sin meter la pata o generar problemas innecesarios.

Aunque la improvisación ocupaba un espacio fundamental, había mucho trabajo atrás para que esas improvisaciones funcionaran. Había un productor casi exclusivamente dedicado a grabar programas de televisión y recortar audios que sirvieran, por un lado, para la parte informativa del programa, y por el otro para la parte humorística. Si bien muchos espacios del programa eran improvisados había otros casi enteramente guionados, como la Siesta Inolvidable de Jorge Halperin. 
La mayoría de los momentos humorísticos o editoriales del programa eran una improvisación a partir de un guión escrito: la apertura de Castelo, los momentos humorísticos de Gillespi y Barragán, y otras intervenciones o dramatizaciones que se hacían al aire (que requerían una importante pre-producción de sonidos ambiente, efectos, música, pistas sonoras, etc.).

La creatividad se vio potenciada por la modernización tecnológica que por un lado permitió mayor rapidez en la grabación y edición de audios, y por el otro, el aumento de la conectividad y el desarrollo de internet facilitaron el acceso a información, los contenidos y las personas.

En 2002 si pasaba algo en París era muy fácil buscar en internet el teléfono de la Embajada Argentina y comunicarse en menos de un minuto con alguien que pudiera explicar en español desde el lugar de los hechos qué había pasado. A partir de entonces ya no fue tan importante para un productor contar con una buena agenda, también había que tener una buena cabeza. No hacía falta tener el contacto en la agenda. Había que saber cómo y dónde buscarlo.

Los diarios, que desde fines de los 90 habían empezado a desarrollar los portales digitales, en la década siguiente empezaron a actualizarlos durante el día, de modo que para los productores comenzó a ser una rutina hacer una pasada por las páginas web de los diarios para ver si había pasado algo importante, o cómo titulaban cada uno. Hasta ese momento para saber qué había pasado durante el día era necesario recurrir a las agencias de cables y ver cada uno de ellos o a lo sumo los "panoramas" que hacían las agencias, para tener un resumen de lo que iba pasando, pero en la mayoría de los casos no eran un anticipo de lo que sería la tapa de los diarios al día siguiente. 


\section{Algunas conclusiones}

Para poner en perspectiva lo que implicaron esos cambios en el trabajo de un productor, unos pocos años antes, en el 2000, yo producía un programa que Juan Castro hacía en la primera mañana (de 6 a 9) de Radio del Plata. Todas las tardes, alguno de los productores del programa pasaba por la radio (varias horas) para seleccionar e imprimir los cables con las principales noticias del día y acercárselos a Juan, para que él llegara informado al día siguiente que arrancaba muy temprano. No existía en ese entonces un lugar donde uno pudiera acceder a esa información online, algo que unos pocos años después fue muy común, y facilitó mucho el trabajo de la producción y los periodistas.

Aunque estas facilidades tecnológicas facilitaron mucho nuestro trabajo también trajeron inconvenientes, en las radios empezó a perder importancia producir información propia y por ende se fue achicando el plantel de personal dedicado a eso. Por otro lado, al consultar todos los periodistas los mismos portales de noticias, el discurso de los medios comenzó a ser cada vez más homogéneo y menos original. Eso era algo bastante común en los programas radiales de la mañana, donde casi todos seguían las noticias instaladas por los diarios (las de la tapa y las de sus páginas interiores), pero se fue extendiendo hacia el resto de los horarios.

Otro de los cambios fue que los estudios de las radios se fueron plagando de televisores. Antes del 2000 era común que hubiera un aparato de TV en los estudios de radio, pero televisores de 20 pulgadas, que estaban en una esquina del estudio (en Radio Mitre estaba en una mesita con rudas), generalmente permanecían apagados. Pero con la proliferación de canales de noticias fue muy común que los estudios de radio comenzaran a llenarse de televisores, cada vez más y cada vez más grandes. No porque hubiera canales 
de noticias las 24 horas comenzaron a suceder mas "hechos noticiables", sino que fue necesario llenar todas esas horas con algunos contenidos, que no siempre eran relevantes pero que "tenían gancho" y se desdibujó la línea entre el periodismo con el espectáculo. Así fue que los hechos de "inseguridad" comenzaron a ocupar más espacio en los canales de noticias, y eso se transmitió al aire de las radios.

Cuando los aparatos de TV empezaron a poblar las radios a ningún conductor/productor se le hubiera ocurrido tomar el audio de una conferencia de prensa directamente de la televisión (en primer lugar porque si era algo importante la radio tendría un acreditado ahí (que hubiera puesto el grito en el cielo si lo excluían de la nota), un tiempo después si había un evento transmitido por la televisión, el cronista de la radio sólo haría la apertura y el cierre de esa transmisión, pero el audio "se tomaría" directamente de la televisión (por cuestiones de calidad). En la actualidad la mayoría de las conferencias de prensas que transmiten las radios lo hacen tomando el audio directamente de la televisión, sin tener ningún periodista propio en el lugar.

El tiempo siguió pasando y los cambios no se detuvieron. Hoy es posible grabar y editar (con calidad profesional) desde cualquier celular, es fácil pedir que un entrevistado envíe un mensaje de voz (o WhatsApp) con calidad para salir al aire, hay páginas especializadas (como Radiocut) que tienen las grabaciones de todas las radios, mas muchísimos audios -los principales del día- ya cortados (eso hubiera sido el sueño de un productor en los 90). A eso hay que sumarle que, entre Twitter, Instagram y YouTube se puede conseguir en minutos cualquier audio, declaración, tema musical que a uno se le ocurra. De hoy o de hace 50 años. 
Todos estos cambios que facilitaron las posibilidades de acceso a la información, que potenciaron la creatividad e hicieron posible realizar cosas que antes hubieran sido imposibles también redundaron en una mayor precarización de los trabajadores de las radios. Hoy en día un programa que antes se hubiera hecho con 6 productores hoy se hace con 2, las radios son cada vez más chicas, sin estudios auxiliares, oficinas de preproducción, ni acreditados especiales; donde la mayoría de la información que ocupa el aire de las radios es tomada de portales de noticias o Twitter, porque las radios ya no producen su propia información y cada vez menos gente realiza más tareas. Pero no todas son malas noticias, en estos tiempos de concentración mediática también han aparecido nuevos soportes como los podcasts y las radios digitales independientes, con suscripción, que permiten nuevas maneras de trabajo y de comunicación con los oyentes, y si bien suponen una esperanza todavía ocupan un lugar pequeño en el universo radiofónico 